\title{
New Acoustics Laboratory at the National Physical Laboratory
}

By DR. G. W. C. KaYe, O.B.E.

$\mathrm{O}$ $\mathrm{NE}$ of the great social ineonveniences in present-day life for large numbers of people is the lack of quietness which modern building design and materials have brought in their wake. The problem is accentuated in the case of the many large blocks of flats and apartment houses which are being erected, all around us, whether for the well-to-do or for the slum dweller. The question of acoustic isolation for the occupants receives
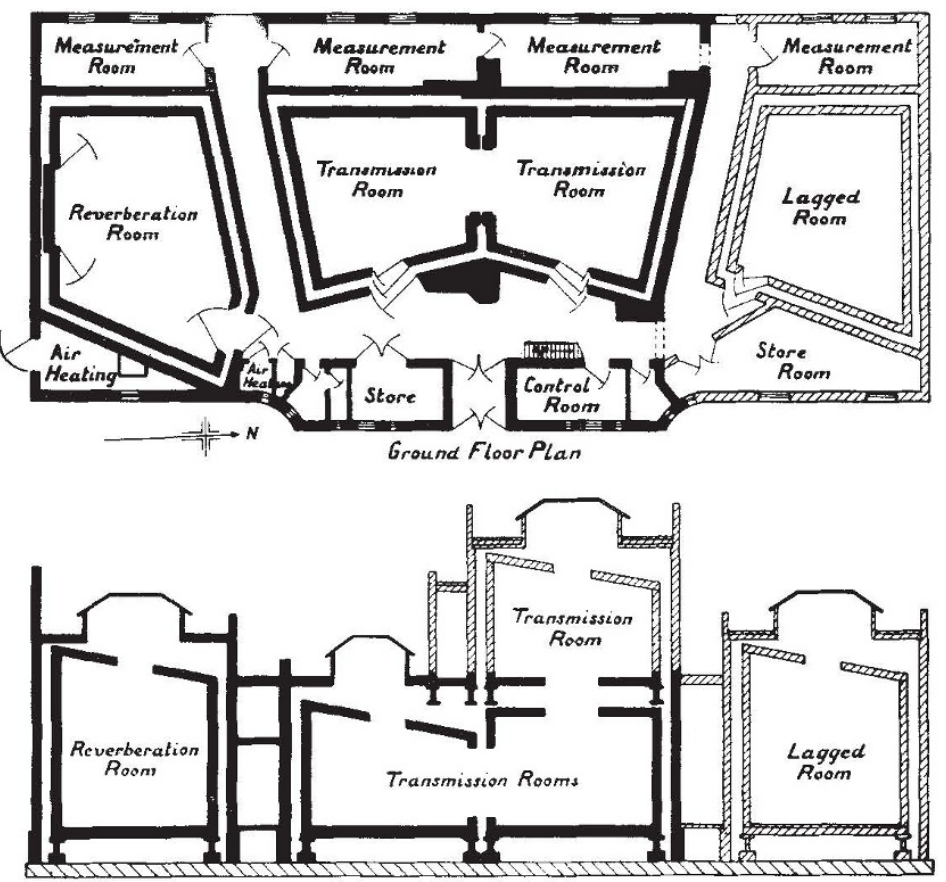

$$
\text { Sectional Elevation. }
$$

Da Proposed new wor:

FIG. 1. New Acoustics Lakoratory at the National Physical Laboratory. for little or nothing. Unfortunately, the present tendency in building is to cut down both weight and thickness, and so for greater silence we must turn to composite structures, in which case design becomes all important. Such designs can only be appraised experimentally, for at present we cannot predict quantitatively their performance from a knowledge of their structure. Much remains to be done, but already designs are available, for example, of light, double air-spaced partitions, which are much more effective sound-proofers than single partitions of the same total weight. Crossties and incorrect separation of the components may be fatal to efficiency. This is illustrated by recent work at the National Physical Laboratory on double windows, which indicates that the separation for ordinary window glass should normally not be less than 4-6 inches, and that at smaller distances the insulating value drops to a minimum which may actually be less than that of one window alone. Apropos of windows, sound insulation is often quite incompatible with open windows, and forced ventilation may be the only solution in such cases.

When we come to deal with noises or vibrations which reach a room via the structure of a building, quite different measures are necessary. Vibrations may often be arrested near the source by resilient undamped devices so loaded as to be of suitably long period. Modern building structures contain noise-transmitting components of a high order-whether steel framework, ferroconcrete, cementbound brickwork, hard plaster, water and radiator systems, sanitary piping, etc. Some form of discontinuity to arrest transmission has to be introduced, and in many cases the problems have still to be solved. Almost all forms of concrete flooring are noisy, and attention is now being given to floating floors, suspended ceilings and various types of floor finishes, to find an effective, yet economically feasible, solution.

The last stage in the attaining of a quiet room is to deal with extraneous noise which has succeeded in gaining admission or which is generated within the room itself. Something can be done to remedy the deficiency of absorbents in a too reverberent room by adding upholstery, curtains, thicker underfelts to carpets and so on. If these things are not in keeping with a room, then we can apply to the walls or ceiling one or other of the absorbents now commercially available, for example, fibre boards or porous plasters, or paung value of a single hom geneous wall notes are easier to stop than low, but design counts 
or one of the hair or asbestos felts covered with perforated or pin-pricked fabric which can be distempered or otherwise decorated. The effectiveness of the latter is noteworthy in that the area of the pin holes may be only a small fraction (less than 1 per cent) of the area of the fabric.

The foregoing will give a notion of some of the acoustical problems which confront the architect, the building industry and the acoustical engineer. It is not impossible that measures to reduce noise to the level demanded by the public may necessitate serious modifications in the accepted methods of construction. Adequate facilities for carrying out investigations on full-scale floors and partitions have not hitherto existed in Great Britain, but the Department of Scientific and Industrial Research has recently embarked on a programme of research, and a start has been made to provide the necessary facilities in the shape of a new acousties Laboratory which has been designed at the National Physical Laboratory, with the cooperation of H.M. Office of Works.

The laboratory, which was open for inspection on the occasion of the annual visitation on June 26, will ultimately form part of the Physies Building. Complete acoustical and electrical isolation is aimed at in the case of the experimental rooms, these at present comprising a reverberation room and a pair of transmission rooms, each with its own measurement room for the operator during the actual observations. Fig. 1 shows a sectional plan and elevation. As will be seen, the enclosing walls, floors and ceilings are of massive masonry, and everywhere double, the inner shell being completely independent of the outer and resting only on insulating piers on separate foundations. The insulation in the piers is slab cork, and provision has been made for the hydraulic lifting of the inner rooms (which weigh 150-200 tons) so that should the cork deteriorate under the sustained heavy load it can be renewed.

Acoustic absorption coefficients have been determined in temporary accommodation at the Laboratory for some years, but unique facilities for the work are now provided by the new reverberation room. This is asymmetric both in plan and elevation : the walls are not parallel nor is the ceiling horizontal, thus assisting in minimising the influence of the natural transverse resonances of the air in the room, as well as promoting the uniform and random distribution of sound which the several reverberation formulæ postulate. The even distribution is furthered by the use of a warble note as a source of sound. The walls of the room are finished in painted hard plaster, and the

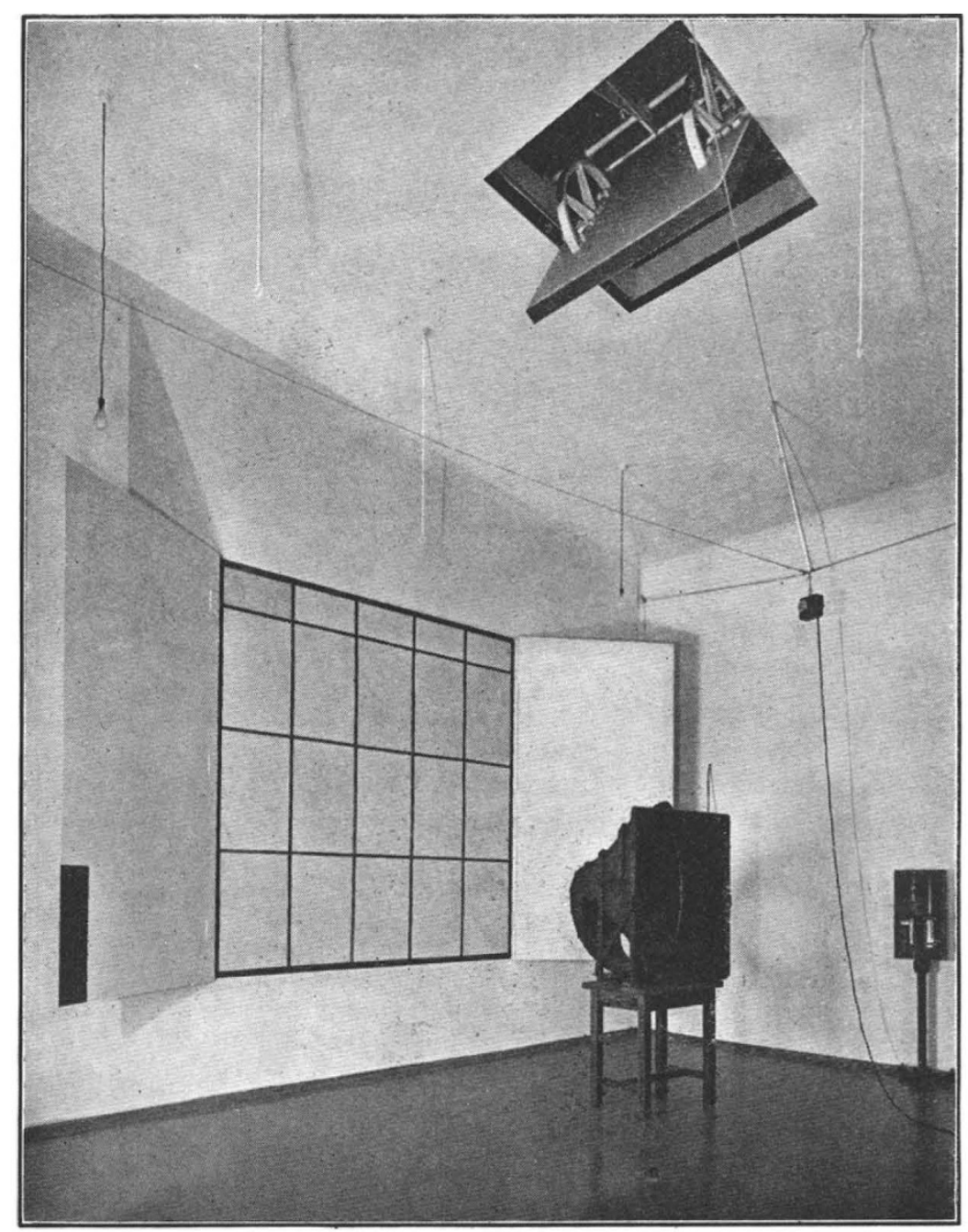

FIG. 2. Reverberation chamber showing loud speaker, microphone and test panel of which the acoustic absorption coefficient is required.

closely-fitting double entrance doors are each of solid steel, the inner being $3 \frac{5}{8} \mathrm{in}$. thick and the outer $2 \frac{1}{2}$ in., and correspond in superficial weight to the adjacent walls. The shutters to the skylight, which are of similar construction, are electrically operated from below.

The volume of the room is about 10,000 cubic feet, and the Sabine reverberation period for a note of 512 cycles per second is about 13 seconds when the room is empty. In one of the walls are steel swing doors (see Fig. 2) covering a shallow recess in which is mounted 100 square feet of the 
material, the acoustic absorption coefficient of which is required. A loud speaker produces one of a range of notes of frequencies from 125 to 4,000 cycles per second, and in each case a microphone and amplifier system affords the decay curve of the average intensity in the room with the test absorbent alternately exposed and covered up by the doors. A thyratron relay device automatically records the decay period for any pre-

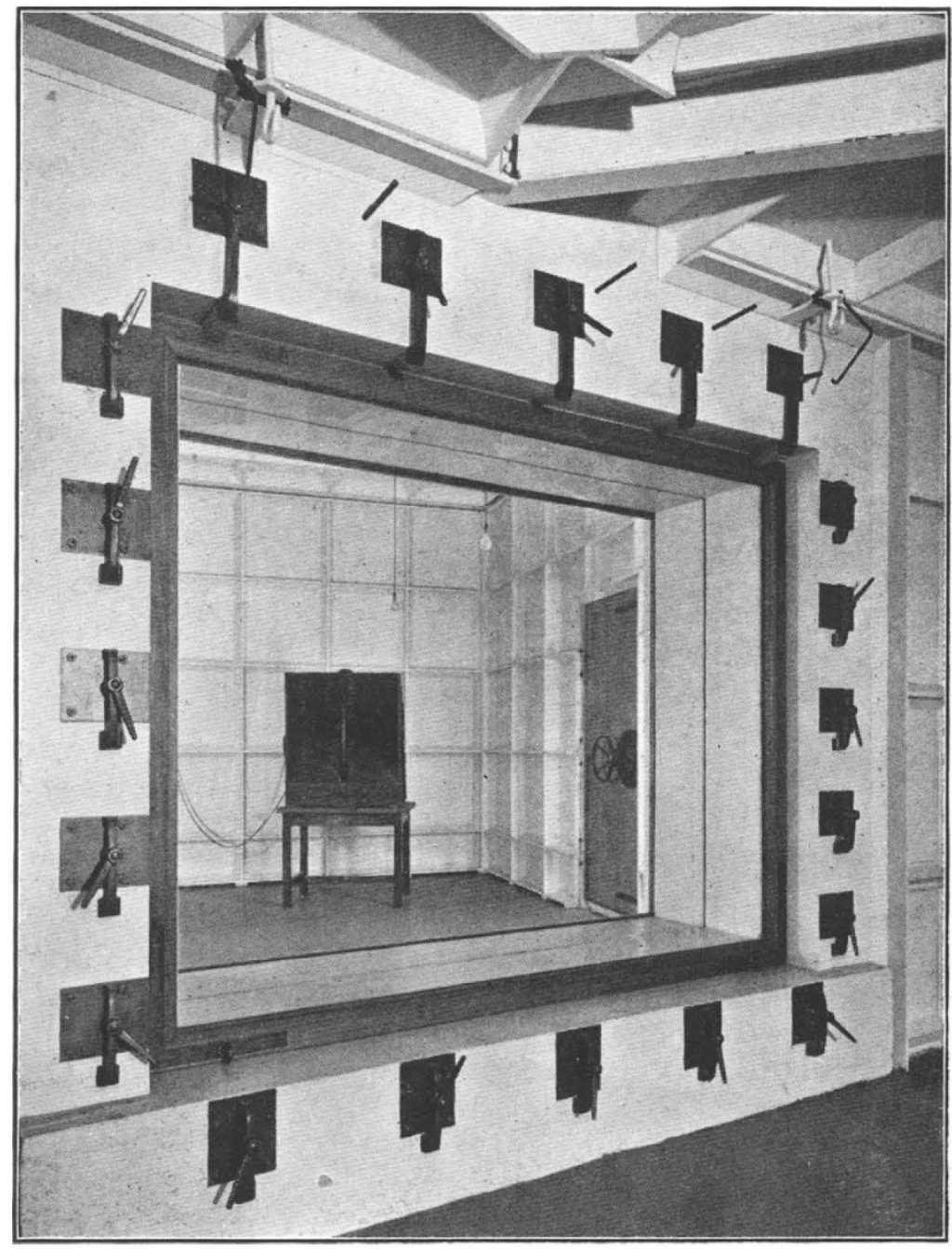

FIG. 3. Transmission rooms showing test aperture for measurement of acoustic isolating values of walls and partitions.

selected intensity drop of decibels. If the air of the room is appreciably humid, it may contribute markedly to the absorption of sounds of frequencies above about 2,000 .

The values of absorption coefficients are known to be susceptible to a variety of influences and the Laboratory is participating in an international inquiry into the dependence of absorbing power on the size, shape and distribution of a test material, its thickness and porosity, the method of mounting, the degree of separation from a backing wall and so on.

The two transmission rooms are on independent foundations, and are of the same irregular shape and general construction as the reverberation room, except that the entrance doors are triple and of solid wood. The test aperture, which is shown in Fig. 3, will take specimens up to about $10 \mathrm{ft}$. $\times 8 \mathrm{ft}$. These are either erected in situ or assembled elsewhere and then mounted in position by the aid of the clamps shown. A runway is provided for transporting heavy specimens. Tests are normally conducted with an exploring microphone in each room and a loud speaker in one of the rooms, a warble note with a selection of frequencies between 100 and 4,000 cycles per second being employed. The position of the microphone can be controlled from the adjacent measurement room and the oscillator exciting the loud speaker together with the microphone and associated amplifier are wholly operated from the electric supply mains. Provision is made so that the walls of the rooms can either be used in a reflecting state, when tests are made with sounds at random incidence, or covered with absorbent when a beam of sound is used. The rooms can readily be adapted for testing the sound attenuation in ventilation ducts and silencers as well as for studying the quietening of machinery.

The ventilation of the building is by pressure feed, and constant temperature heating in the experimental rooms is aimed at by passing warmed air between the double walls. Concentric cable is used in the wiring of the experimental equipment, and when desired, the entire building or any selected section of it can be rendered electrically isolated by cutting off all external power supplies, requirements being then met from a battery.

It is hoped that it will not be long before an upper transmission room is erected (see Fig. 1) so as to permit acoustic tests on floors for which provision has been made by constructing a ceiling aperture to take floor specimens $8 \mathrm{ft} . \times 7 \mathrm{ft}$. and upwards. In the meantime, provisional arrangements are being contrived. A room with heavily lagged walls is also contemplated to provide for the absolute calibration of microphones and other purposes. The investigations in the new Laboratory will be implemented by 'field tests' on actual buildings so as to take into account the factors of construction and workmanship. 